\title{
Quantum effects in cryocrystals in a wide temperature range
}

\author{
A. Leont'eva \\ O.O. Galkin Donetsk Physics-Technology Institute of the National Academy of Sciences of Ukraine \\ 46 Nauki Ave., Kyiv, Ukraine \\ E-mail: tonya.leont@gmail.com
}

\section{A. Prokhorov}

Yaroslav-the-Wise Novgorod State University, 41 Bolshaya St. Petersburg Str., Veliky Novgorod 173003, Russia

\section{Romanusha}

Ukrainian Engineering Pedagogical Academy, 16 Universytetska Str., Kharkiv 61003, Ukraine

\section{Efimov}

Institute of Solid State Physics RAS, 2 Academician Ossipyan Str., Chernogolovka 142432, Russia

\section{Received October 24, 2018}

\begin{abstract}
Due to the ever-increasing interest in cryocrystals in scientific and applied problems, a thorough study of their various properties and characteristics is necessary. The analysis of experimental anomalies in a number of physical properties of quantum cryocrystals (helium, hydrogen and methane) is presented in the low-temperature region. In this temperature region thermal fluctuations decrease sharply, whereas the role of quantum fluctuations stays dominant. This is manifested not only in the translational motion of atoms or defects in such crystals (as helium, neon), but also in the rotational degrees of freedom, for example, in the properties of solid methane and hydrogen.
\end{abstract}

Keywords: helium, hydrogen, methane, argon, quantum effects, quantum parameters, rotational heat capacity.

\section{Introduction}

An interest in studying various properties and features of cryocrystals has recently increased taking into account the possibility of its scientific and applied problems. The development of models for computer calculations and experimental technique at low temperature has recently renewed an interest in manifestations of the quantum properties of crystals. First of all, this concerns quantum cryocrystals in which the amplitude of quantum oscillations of atoms is of the same order of magnitude as the interatomic distances. Due to large zero-point vibrations, the wave functions of atoms are overlapped sufficiently. This leads to subbarrier tunneling of atoms, for example, the motion of $\mathrm{a}^{3} \mathrm{He}$ atom in a ${ }^{4} \mathrm{He}$ matrix or the helium atom exchange with a vacancy or defect. The de Boer parameter is an indicator of the manifestation of quantum effects in the system of atoms and molecules. It is defined as the ratio of the corresponding de Broglie wave of an atom or molecule in the equilibrium position to the distance between particles in a crystal.

Traditionally, a crystal is reckoned to quantum crystals in the case when the de Boer parameter $\Lambda \cdot$ is comparable with crystal distances and has the value $\sim 0.1$. For example, ${ }^{3} \mathrm{He},{ }^{4} \mathrm{He}, \mathrm{H}_{2}$ have $\Lambda^{*} \cdot>0.3$ [1]. However, the manifestation of quantum properties is also observed for elements and compounds in which the quantum kinetic energy of particles at low temperatures is much greater than the energy of thermal vibrations $k_{B} T$. For instance, crystal methane $\mathrm{CH}_{4}$ ("quantum rotator") can also be assigned to quantum crystals, if one takes into account not only the de Boer longitudinal parameter. As in the case of solid hydrogen, the rotating quantum parameter $\lambda_{\text {rot }}$ for methane [2] (Tables 1 and 2) is large enough. Unfortunately, in the recent review [1], the rotational quantum oscillations in cryocrystals are not even mentioned. 
Table 1. Values of the quantum de Boer parameter for $\mathrm{He}, \mathrm{H}_{2}$, $\mathrm{CH}_{4}, \mathrm{Ne}, \mathrm{Ar}$ cryocrystals [1]. Here $\lambda(\varepsilon)$ is the de-Broglie wave length, $r_{0}$ and $\varepsilon$ are the Lennard-Jones potential parameters

\begin{tabular}{c|c|c|c|c|c}
\hline \hline Cryocrystals & Helium & $\begin{array}{c}\text { Hydrogen } \\
\text { Para- } \\
\text { hydrogen }\end{array}$ & Methane & Neon & Argon \\
\hline \hline $\begin{array}{c}\text { Quantum de Boer } \\
\text { parameter }\end{array}$ & 2.7 & 1.79 & 1.48 & 0.55 & 0.16 \\
$\Lambda^{*}=\frac{\lambda(\varepsilon)}{r_{0}}=\frac{\hbar}{r_{0} \sqrt{m \varepsilon}}$. & & 1.78 & & & \\
\hline \hline
\end{tabular}

Notes: here we show argon for comparison, it's quantum parameter $\Lambda^{*}$ is by order of magnitude smaller than the parameter for helium, hydrogen or methane. In this case argon crystal may be considered as a "classical" one.

Table 2. Values of the rotational quantum de Boer parameter for $\mathrm{H}_{2}, \mathrm{CH}_{4}, \mathrm{CD}_{4}$, and $\mathrm{CO}_{2}$ [2]

\begin{tabular}{c|c|c|c|c}
\hline \hline Cryocrystals & Hydrogen & Methane & $\begin{array}{c}\text { Deuterated } \\
\text { methane }\end{array}$ & $\begin{array}{c}\text { Carbon } \\
\text { dioxide }\end{array}$ \\
\hline $\begin{array}{c}\text { Rotational quantum } \\
\text { de Boer parameter }\end{array}$ & 4.78 & 0.627 & 0.318 & 0.0431 \\
$\lambda_{\text {rot }}=\frac{2 \pi \hbar}{\sqrt{I U_{0}}}$ & & & & \\
\hline \hline
\end{tabular}

Notes: here $I$ is the moment of inertia, $U_{0}$ is the potential barrier.

The rest cryocrystals, like $\mathrm{CO}_{2}$, are characterized by extremely low values of the rotational quantum parameter.

In this article we summarize a number of experimental manifestations of quantum effects for various kinds of motions in crystals, which can be regarded as quantum ones. It should be noted that recent articles do not provide an experimental evidence of the quantum nature of such crystals.

\section{Experimental manifestations of the quantum nature of cryocrystals-solid helium, hydrogen, and methane}

\subsection{Helium}

The de Boer parameter has the greatest value for crystalline helium. So, the de Boer parameter is $\Lambda^{*}=3.07$ for ${ }^{3} \mathrm{He}$ and is equal 2.7 for ${ }^{4} \mathrm{He}$. The history of manifestation of the quantum behavior of defects in quantum crystals began with the work of Andreev and Lifshitz [3,4], in which they theoretically predicted the nonclassical nature of the mobility of atoms in crystals with large de Boer parameter and the possibility of existence of quantum defects, for example, "vacancions", "defectons", "impuritons". The most pronounced quantum manifestations are observed in the motion of defects in helium crystals. In particular, the following facts were experimentally found:

1. The mobility of ${ }^{3} \mathrm{He}$ impurities ceases to depend on temperature with cooling below $1 \mathrm{~K}$ [5]. This behavior is explained as a transition to the sub-barrier motion of ${ }^{3} \mathrm{He}$ atoms.
2. Melting waves were observed on the surface of helium crystals - the effect of a weakly dissipative displacement of atoms at the first-order phase transition from a superfluid liquid to a crystalline phase and vice versa [6]. It is assumed that the surface point defects are delocalized, quantum defects appear and their superfluidity arises with the increasing tunnel effects $[3,4]$. Apparently, the observation of anomalously high crystallization rates for some crystalline planes of pure ${ }^{4} \mathrm{He}$ can be referred to the same quantum manifestations [7].

3. Along with magnetic impurity ${ }^{3} \mathrm{He}$ injected charges can be used as probe particles whose motion is fairly easy to detect in ${ }^{4} \mathrm{He}$ crystals. The motion of charges in the helium lattice is determined by their exchange with vacancies. The influence of quantum oscillations in the samples of solid ${ }^{4} \mathrm{He}$ grown at a pressure of $30-32 \mathrm{~atm}$ is most clearly manifested for positive charges movement, the motion of which is determined by the concentration and mobility of vacancies. A feature of the positive charges in solid helium is the existence of a region of compressed helium around the charge, which is formed due to the van der Waals attraction of neutral helium atoms to a positive ion ${ }^{+} \mathrm{He}$. In a liquid, this polarization attraction leads to the formation of a charged cluster consisting of a charge covered by several layers of solid helium [8]. The motion of such a complex in solid helium is defined by a consecutive exchange with vacancies. At high temperatures $(T \sim 1-2 \mathrm{~K})$, the mobility of charges $\mu_{+}$(and their velocity $v_{+}$) is explicitly described by the thermal activation exponential dependence $v_{+} \sim \mu_{+} \sim$ $\sim \exp \left(-\varepsilon_{+} / T\right)$. The exponent of the charge diffusion coefficient, estimated from the Einstein relation $D_{+}=\mu_{+} k T / e$, turned out to be close to the exponent of the diffusion coefficient of ${ }^{3} \mathrm{He}$ impurity in the ${ }^{4} \mathrm{He}$ matrix.

The absolute values of $D_{+}$and $D_{3}$, as well as the characteristic activation energies of $\varepsilon_{+}, \varepsilon_{3}$ and vacancies $\varepsilon_{v}$ [9] are the cause of a basis for the development of vacancy mechanisms of charge motion. In this model the rate of charge transfer is determined by the interaction of an ion with vacancies, i.e., by the relation $v_{+} \sim n_{v} D_{v} \sigma_{v}$, where $n_{\nu}$ is the concentration of vacancies, $D_{v}$ is the diffusion coefficient of vacancies, $\sigma_{v}$ is the effective cross section for vacancy or "vacancion" scattering on a charge or the probability of their exchange of the places. If we assume that the inflections of ions velocities at $T<0.7 \mathrm{~K}$ in Fig. 1 are related to the change in a transport mechanism, for example, the transition from thermally activated (TA) diffusion to quantum tunneling. We may write $D_{+}=D_{T A}+D_{Q}$, where $D_{T A} \sim \exp \left(-\varepsilon_{+} / T\right)[10]$, at the additivity of these two mechanisms - quantum and thermal activate. The dependence of $D_{Q}$ on temperature, calculated from the data for different crystals at different pressures, is shown in Fig. 2.

An increase in the mobility of defects with cooling of the crystal is explained by a decrease in the scattering of quasiparticles (quantum defects - "defectons") on phonons [3]. A further decrease in ion ("defecton") mobility 


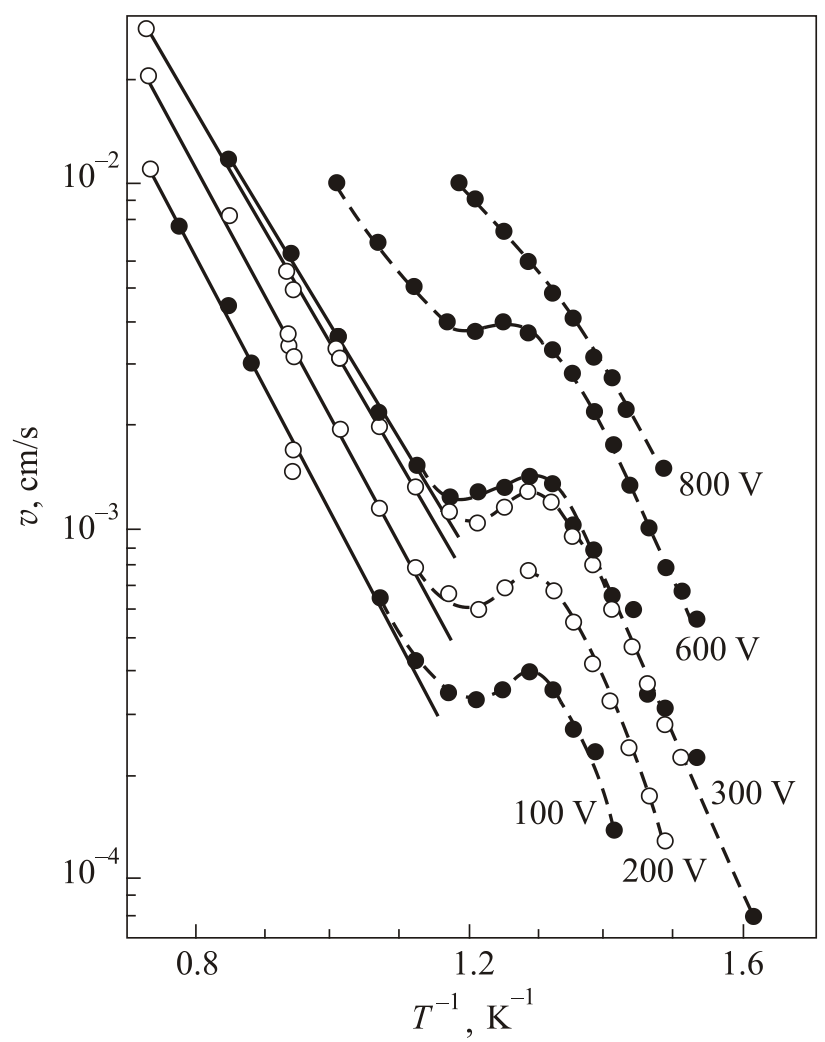

Fig. 1. Temperature dependence of positive ions velocity in two samples of solid helium, grown at $P=31.2 \mathrm{~atm}$ (open circles) and $31.0 \mathrm{~atm}$ (closed circles) at different electric field stresses.

occurs due to the static failure of quantum subbarrier tunneling levels, taking into account different nature of the exchanging particles (charges and vacancies) and the additional energy of the electric field for moving the charges. The cooling of a quantum crystal reduces the dynamic probability of coincidence of the levels for the quantum motion of defects and their interaction with charges [11]. The temperature range of the anomalous charge mobility behavior in weak fields and the diffusion of the magnetic impurity ${ }^{3} \mathrm{He}$ in ${ }^{4} \mathrm{He}$ matrix coincide $(T<0.7 \mathrm{~K})$. This indicates that the mechanism of anomalous motion of such energetically different particles (isotope ${ }^{3} \mathrm{He}$ and cluster positive charge with surrounding deformations), apparently, have the same nature, the vacancy mechanism of motion. The features of the interaction of quantum vacancies ("vacancions") with isotopes, whose concentration is sufficiently high, or with microscopic distortions of the lattice density around the positive charge, determine different temperature dependencies at temperatures below the thermoactivation region. Estimation of the quantum mechanical band of the motion of charged particles gives a value of $\Delta_{+} \sim 10^{-6} \mathrm{~K}$, while the band width for the "impurity" has appreciably larger value $\Delta_{3} \sim 10^{-4} \mathrm{~K}[12]$.

\subsection{Hydrogen}

The influence of quantum effects is particularly great in case of solid helium and hydrogen because of the small

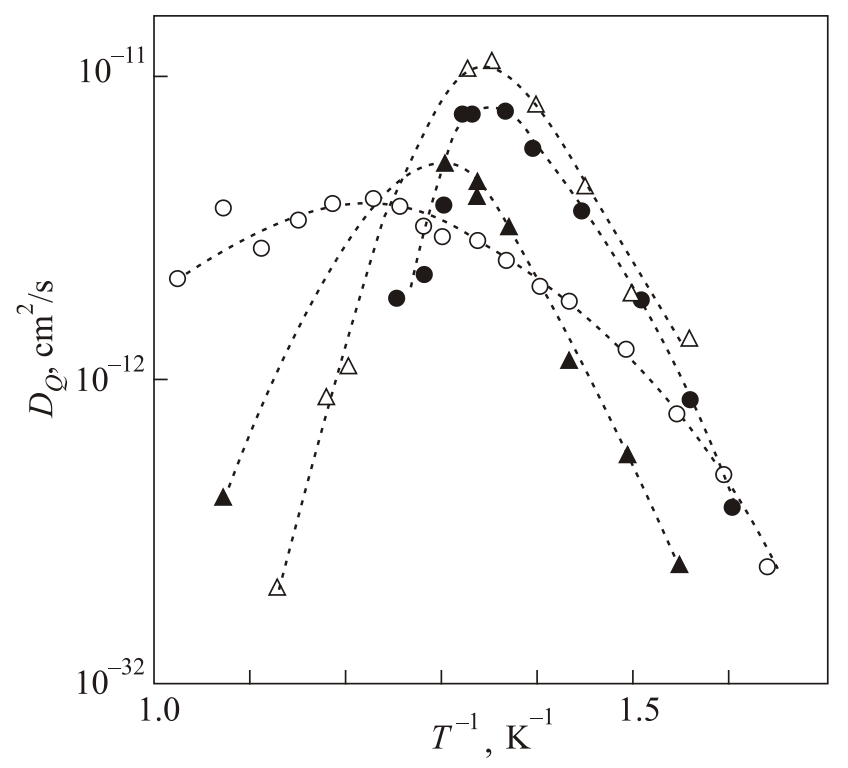

Fig. 2. Temperature dependence of $D_{Q}$, calculated from positive ion velocity for helium crystals growth at different pressures (open circles $-P=28.8$ bar, closes circles -31.3 , open triangles -33.0 and closed triangles -35.9 bar). Applied electric field $U=300 \mathrm{~V}$.

mass of helium atoms and hydrogen molecules and the comparatively weak interparticle interaction and the quantum demonstration is noticeable throughout the entire region of existence of the crystalline state of both crystals. For solid hydrogen, the manifestation of quantum behavior could be observed at the motion of such lattice defects as dislocations when studying deformation of the samples.

\subsubsection{Creep of solid hydrogen}

The plasticity of normal hydrogen $n-\mathrm{H}_{2}$, containing $75 \%$ of ortho-hydrogen and $25 \%$ of para-hydrogen $p-\mathrm{H}_{2}$, was studied by the creep method in a wide range of temperatures and stresses. The measurements were carried out on fully transparent polycrystalline samples with grain size of $0.5-1.0 \mathrm{~mm}$ [13]. The experiments focused on the study of the steady-state creep $\varepsilon=\Delta l / l$. Its duration $\varepsilon(t)$ increased with decreasing temperature or with decreasing value of the applied load $\sigma$. At this stage, the strain rate $d \varepsilon / d t$ was calculated.

It was found that, above $10 \mathrm{~K}$, the strain rate of $n-\mathrm{H}_{2}$ is extremely sensitive to small changes of temperature. At $T$ below $10 \mathrm{~K}$, the fall inćdecreases with reducing temperature, and at helium temperatures the strain rate is practically independent from temperature (Fig. 3). Solid hydrogen exhibits nonzero strain rates at a steady stage even at very low loads. This sharply distinguishes hydrogen among other cryocrystals by the influence of quantum properties, which comes out through its plasticity and dislocation motion.

There is some appearance of the quantum phenomena in solid hydrogen associated with the pining of dislocations in the regions of short-range orientational order arising in 


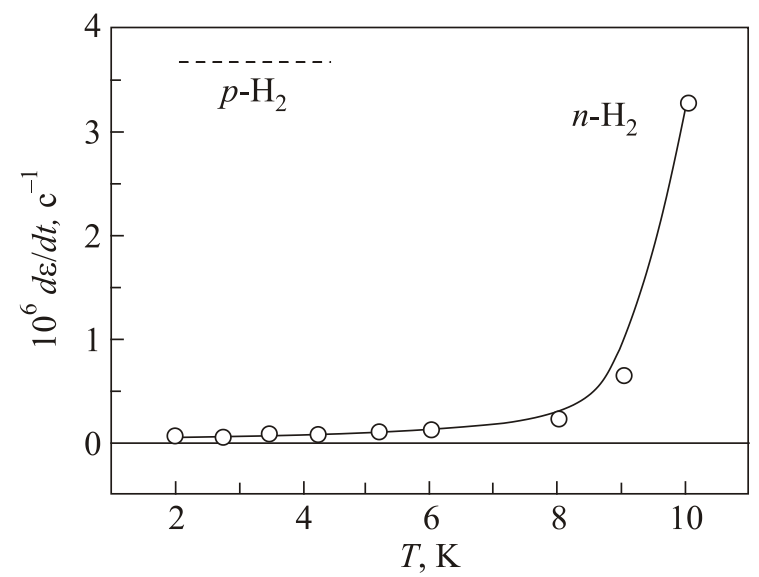

Fig. 3. Dependence of the steady-state creep rate of solid hydrogen on temperature. The curve corresponds to a sample of normal hydrogen $(75 \%$ of ortho-modification and $25 \%$ of para-hydrogen). The creep rate at helium temperatures is different from zero. The dashed line corresponds to pure para-hydrogen, $\varepsilon$ is 50 times higher than that for normal hydrogen and absolute temperature independent [14].

an orientationally disordered crystal as a result of quadrupole-quadrupole interaction of neighboring ortho-molecules. Indeed, the formation of crystals from hydrogen vapor molecules (i.e., para-hydrogen, $p-\mathrm{H}_{2}$ ) leads to an increase in the strain rate by a factor of 50 (!) compared to normal hydrogen containing an ortho-impurity (Fig. 4). Thus, disordered systems consisting of the ortho-para hydrogen molecules substantially reduce the creep rate of solid hydrogen [14].

A sharp increase of mobility of dislocation and the temperature independence of their velocity for hydrogen without the orientational disordering indicate the quantum mechanical mechanism of their motion. The possibility of the existence of two-dimensional superfluidity on the surface of hydrogen crystals was pointed out in [15]. Similar con- ditions can also arise for the diffusion of hydrogen molecules during the motion of dislocations in a force field.

\subsubsection{Low-frequency internal friction of solid hydrogen}

The effect of quantum phenomena on creep and plasticity is also observed in the experiments on low-frequency internal friction (LFIF) of solid hydrogen, when the damping decrement of the system for torsional vibrations with small amplitude has been measured. The investigations of the temperature dependence of LFIF and shear modulus $G \sim f^{2}$ (Fig. 4) in the temperature range of 2-12.5 K were carried out on free (separated from the container walls) samples of solid hydrogen $n-\mathrm{H}_{2}$ by the inverse torsional pendulum [16] using the methods described in [33].

For comparison, Fig. 4 also shows the experimental results of LFIF for solid argon, the quantum de Boer parameter of which is smaller by orders of magnitude than that for hydrogen (Table 1). This allowed us to consider argon in a series of cryocrystals as a "classical" object convenient for comparisons. First of all, it is worth paying attention to the tendency of increasing the absorption of energy at the LFIF in $n-\mathrm{H}_{2}$ as the temperature decreases. Thus, $\mathrm{Q}^{-1}$ increases from $4 \cdot 10^{-3}$ at $7 \mathrm{~K}$ to $1.5 \cdot 10^{-2}$ at $2 \mathrm{~K}$, whereas the tendency of the temperature dependence of internal friction for argon practically does not change and remains at a relatively low level (lower than $10^{-3}$ ). Such an anomalous rise in the LFIF of solid hydrogen with decreasing temperature, may be explained by the effect of quantum properties of motion of dislocations. The same anomalous behavior is observed for the shear modulus $G(T) \sim f^{2}$ for $n$-hydrogen in the interval $0.15-0.95$ of reduced temperatures.

The hardness of hydrogen samples practically does not change throughout almost the entire temperature range of their existence, remaining at a constant level close to $G(T=0 \mathrm{~K})$, while argon samples become harder. The absolute values of $f^{2}$ in hydrogen are lower by an order of magnitude than those in argon in scale $T / T_{m}$ at cooling.
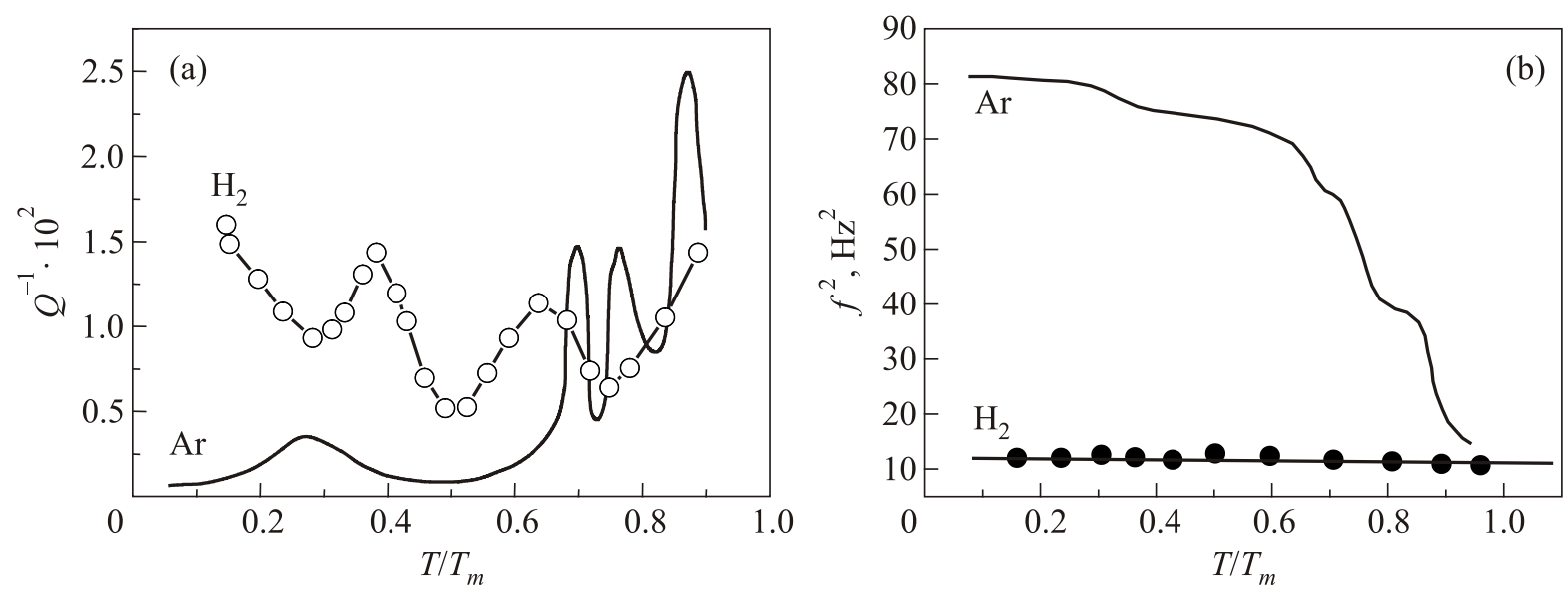

Fig. 4. Dependencies of energy absorption for free torsional oscillations for hydrogen and argon samples (a) and the shear modulus for the same samples (b) on reduced temperature. 
The indicated features of LFIF in solid hydrogen the following: an anomalous increase in the background of internal friction with a decrease in temperature in the region $T / T_{m}<0.5$, the relative constancy of the shear modulus and its low values throughout the studied temperature range are apparently related to the behavior of temperature-independent quantum phenomena.

\subsection{Methane}

For simple atoms, such as helium or argon ones, occupying lattice sites in crystals, only quantum-mechanical exchange is possible at very low temperature. All the above examples of the macroscopic manifestation of quantum properties were associated with the delocalization of defects in crystals with the high de Boer parameter.

Crystals formatted from molecules have the possibility for quantum rotational motion of the molecules as well as thermomechanical mechanisms and quantum mechanisms of translational displacement.

At sufficiently low temperature, when the quantum fluctuations stay dominant, two types of disordering quantum rotational phenomena take place: first, at $\lambda_{\text {rot }} \sim 10^{-5}$, the system goes over into a radially ordered but orientationally disordered state when different atoms in molecules are rotated on the lattice position. For much larger $\lambda_{\text {rot }} \sim 0.1$, a transition to a disordered state takes place [17].

In this sense the quantum manifestations of rotational displacements can be found in crystals with simple molecules such as hydrogen and methane, for which the quantum rotational parameter $\lambda_{\text {rot }}$ has the values $>0.1$.

\subsubsection{Creep of solid methane}

The creep of solid methane $\left(T_{\mathrm{tr}}=90.4 \mathrm{~K}\right)$ was studied in the most interesting low-temperature region $(4-23 \mathrm{~K})$, in which quantum features of methane plasticity were observed.

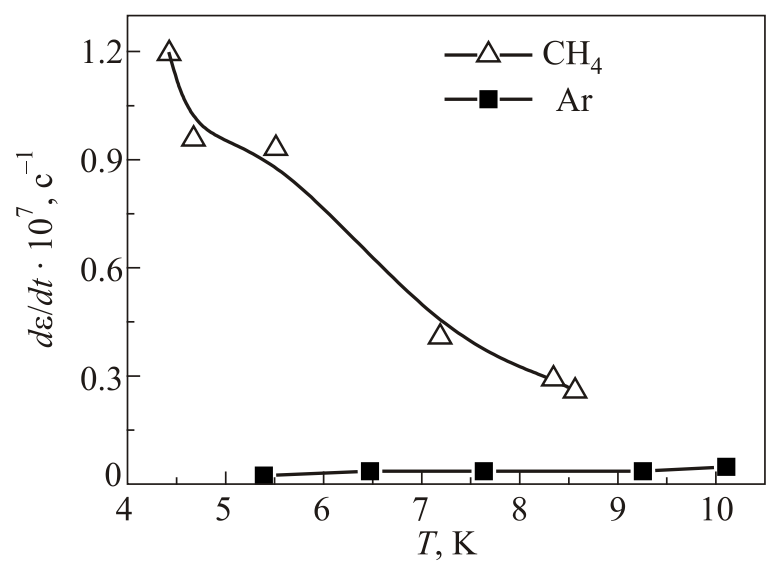

Fig. 5. Temperature dependence of the rate of stationary creep of solid methane and argon in the temperature range of 4-10 K. Solid argon in this temperature interval has the creep rate very close to zero.

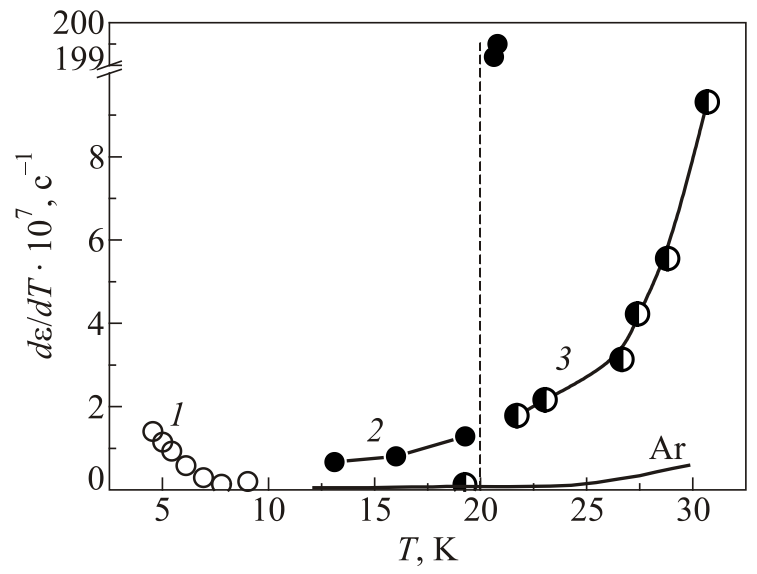

Fig. 6. Temperature dependence of $\dot{\varepsilon}(T)$ for crystalline methane at various loads, $\mathrm{g} / \mathrm{mm}^{2}: 440$ (1), 300 (2), 200 (3). The solid line is practically zero velocity $\dot{\varepsilon}$ for argon. The vertical dashed line corresponds to the temperature of the phase transition in solid methane.

Methane samples with a working section $30 \mathrm{~mm}$ in length and $6 \mathrm{~mm}$ in diameter were crystallized from the liquid phase and they were completely transparent without visible defects. The purity of the feed gas was $99.99 \%$. The sample was detached from the container wall by pumping methane vapor over the sample at a temperature close to the triple point. At the same time, grain boundaries with linear dimensions of 2-4 mm were identified. The method for studying creep is described in [20]. Figure 5 shows an anomalous increase in the rate of stationary creep $\dot{\varepsilon}$ as temperature decreases in the interval of $10-4 \mathrm{~K}$. The limiting value of $\dot{\varepsilon}$ at $T=4.5 \mathrm{~K}$ and $\sigma=200 \mathrm{~g} / \mathrm{mm}^{2}$ is $\dot{\varepsilon}=1.2 \cdot 10^{-7} \mathrm{~s}^{-1}$, which exceeds $\dot{\varepsilon}$ at $9 \mathrm{~K}\left(0.3 \cdot 10^{-7} \mathrm{~s}^{-1}\right)$ by 4 times [18]. We compare the results of creep measurement of methane with the results of studies of crystalline argon as the standard of classical behavior of creep.

The general form of the temperature dependence of the creep rate $\dot{\varepsilon}$ of methane at different loads in the range of $4-30 \mathrm{~K}$ is shown in Fig. 6. As in Fig. 5, the creep of argon is practically brittle and with zero creep rate below $23 \mathrm{~K}$ [19]. An increase in the load $\sigma$ leads only to a jump in the instantaneous creep of argon, but at the steady-state stage of creep is equal to zero $\dot{\varepsilon}=0$ within an experimental error [20].

An increase in the rate of stationary creep of methane with decreasing temperature (below $10 \mathrm{~K}$ ), unlike argon, is apparently associated with quantum effects in methane.

\subsubsection{Thermodynamic indicators of the quantum nature of crystalline methane}

In 1953 Tomita [21] discovered an unexpected phenomenon in NMR studies of solid methane: methane molecules in the solid state rotate in a wide range of temperatures, up to $65 \mathrm{~K}$, when (according to the NMR data) the 


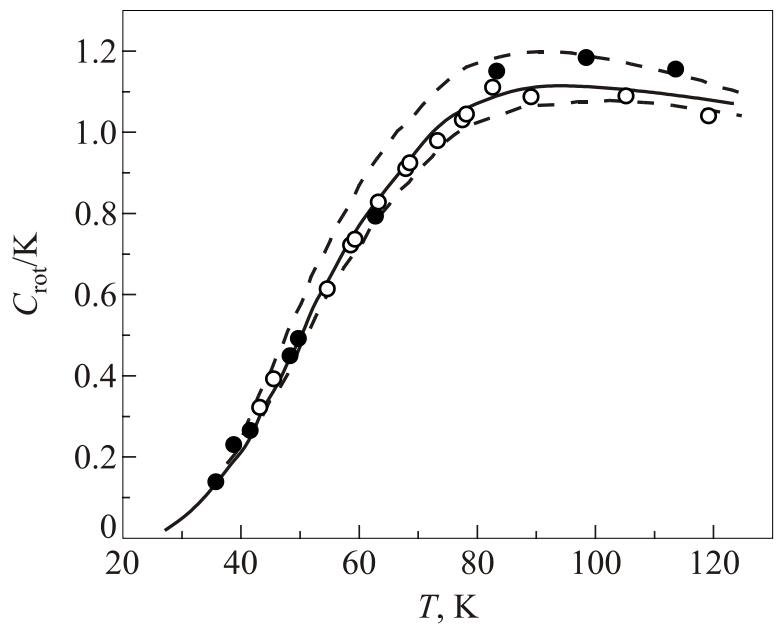

Fig. 7. Temperature dependence of rotational heat capacity for gaseous deuterium [23] with a maximum near $90 \mathrm{~K}$.

character of rotation of $\mathrm{CH}_{4}$ molecules changes sharply, like as upon melting. The rotation of molecules in the $\mathrm{CH}_{4}$ lattice allows suggesting that solid methane is a quantum crystal throughout the entire range of existence of the solid phase.

These experimental data of Tomita directed us to analyze the rotational heat capacity of this cryocrystal. Available literature sources showed that the entire rotational heat capacity of methane and other gases has been calculated only for an ideal quantum gas. One of the first proofs of the quantum nature of rotational motion was paper [22] by the example of gaseous deuterium. Figure 7 presents the calculated and experimental results of the temperature dependence of heat capacity for gaseous deuterium. The main feature of such dependences is the presence of a characteristic maximum at $\mathrm{T}_{0}$, which is a purely quantum effect [34].

When analyzing the experimental works of other authors on methane, it was unexpectedly found that the special temperature of Tomita $(65 \mathrm{~K})$ manifests itself in a large num-

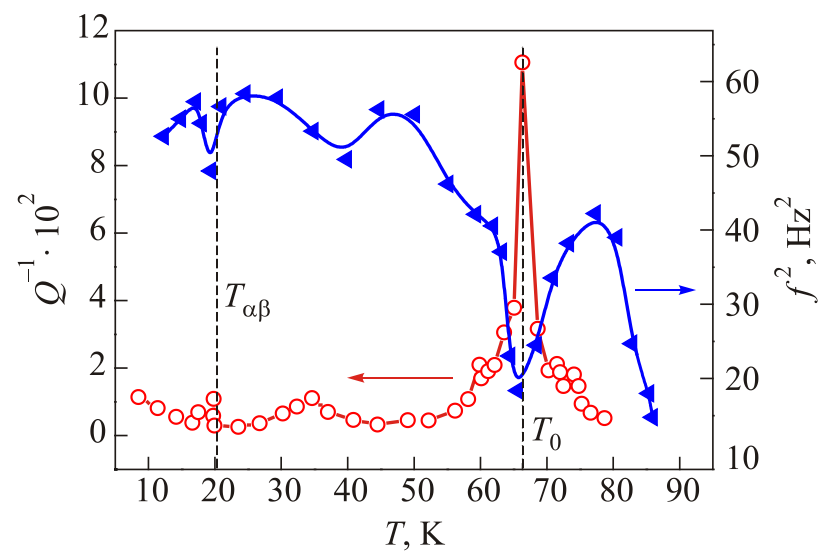

Fig. 8. Temperature dependence of LFIF $Q^{-1}$ and square of torsion oscillation frequency $f^{2}$ of solid methane [32]. ber of physical properties of solid methane in the form of anomalies in the temperature dependences of these properties [32]. These anomalies were especially pronounced in the investigations of low-frequency internal friction [24], nuclear magnetic resonance [21], adhesion [25], etc., in which the anomalies at $60-70 \mathrm{~K}$ even significantly exceeded the anomalies at $\alpha-\beta$ phase transition. It is seen (Fig. 8) that near $65 \mathrm{~K}$ there is a peak of LFIF, which is much greater than the anomaly at $\alpha-\beta$ transition. At these temperatures, a sharp decrease in the shear modulus is also observed, which is apparently due to the transition of solid methane to a state close to a liquid [21]. We should also note a significant increase in LFIF as the temperature decreases in the temperature region $T$ below $20 \mathrm{~K}$, which indicates quantum effects, as in the case of the most quantum manifestation of rotational motion in hydrogen crystal [16].

It should be noted that new reports have recently appeared in which the anomalies described above are confirmed $[26,27,35]$.

\subsubsection{Topons}

We will consider the rotational component of the thermodynamic functions of solid methane in the framework of the ideal gas model consisting of topon quasiparticles (tops). The thermodynamics of an ideal quantum gas with rotational degrees of freedom of molecules was created in the late 1920s [36]. The rotational component of the heat capacity $C_{\text {rot }}$ of an ideal gas consisting of tops is a function of the dimensionless temperature

$$
C_{\text {rot }}=f(\tau), \quad \tau=\frac{T}{T_{\text {rot }}} . T_{\text {rot }}=\frac{\hbar^{2}}{2 \kappa I}
$$

( $k$ is the Boltzmann constant, $I$ is moment of inertia of the molecule-gyroscope). To calculate the temperature dependence of the rotational heat capacity of methane, it is required to calculate the corresponding partition function

$$
Z=\sum_{n=0}^{\infty} g_{n} \exp \left(-\frac{n(n+1)}{\tau}\right)
$$

where $g_{n}$ is the multiplicity of degeneracy of the $i$ th state of the top, $\tau$ is the dimensionless temperature determined by the relation (1).

All the specifics of thermodynamics of a particular ideal quantum gas in terms of dimensionless temperature lies in the nature of the dependence of the multiplicity of degeneration of the top on the number of its state. The dependence of $g$ on $n$ is entirely determined by the symmetry properties of the molecule-top. Unlike other degrees of freedom, the rotational component of the heat capacity is a non-monotonic function of temperature: before rushing to zero at $T \rightarrow 0$, the rotational heat capacity increases to some maximum value at $T=T_{0}$ and then only rushes to zero. The value of 
the rotational heat capacity at the maximum point of $C_{\text {rot }}\left(T_{0}\right)$ is greater than its classical value, achieved at high temperatures. [37].

Using the concept of quasiparticles (or, what is the same thing, elementary excitations) allows us to consider a system of interacting particles as an ideal (or almost perfect) gas of particles, whose parameters are usually determined from experimental data. The quasiparticles include phonons, electrons in crystals, polarons, etc.

It is a striking fact that, until now, the thermodynamic approach to the properties of solid methane has been completely absents in literature. Since 1920, up to the present time (Landau's work [37]), the thermodynamics of methane has been studied only for an ideal quantum gas. It led to the need to create a model of the rotational heat capacity of solid methane, where the rotational degrees of freedom are described within the concept of the corresponding quasiparticles called topons.

In particular, it was suggested in [28,29] that in solid methane due to the intermolecular interaction the collective excitations of the rotational degrees of freedom of $\mathrm{CH}_{4}$ molecules should be considered instead of the independent rotation of individual molecules as for a gas. Such a conception corresponds to the work of Pauling [30]. A topon is characterized by a single parameter the effective moment of inertia. A topon is a spherical top not because of its symmetry. Therefore, the degeneracy of the levels of a topon is determined by the relation $g_{n}=(2 n+1)^{2}$, where $\mathrm{n}$ is the level number [31].

The plot of the temperature dependence of rotational heat capacity for solid methane has the form shown in Fig. 9 [28]. The maximum corresponds to temperature $T_{0}=$ $=60 \mathrm{~K}$.

We may identify the temperature of a sharp change in the character of rotation of solid methane moleculeswith the maximum of the rotational heat capacity $T_{0}$ according

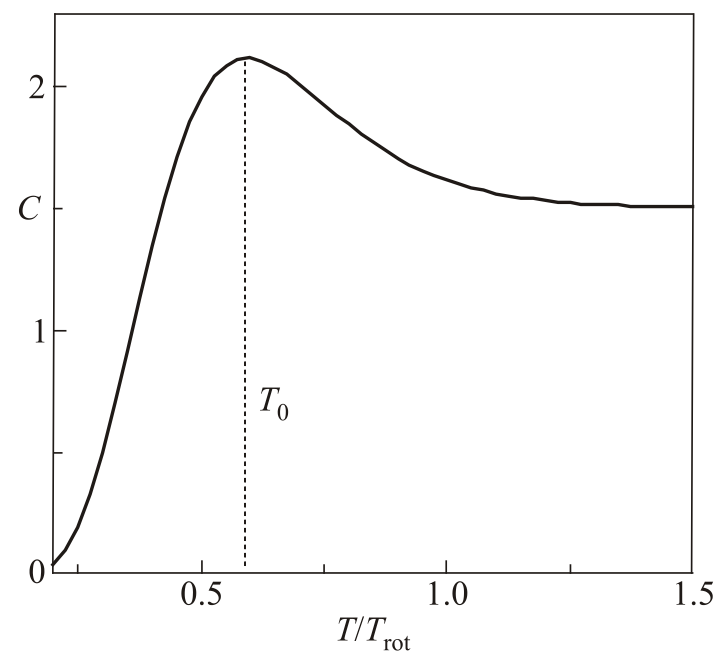

Fig. 9. Temperature dependence of the rotational heat capacity $C$ of topons on the dimensionless temperature $T / T_{\text {rot }}$. to the Tomita's result. Then we find a rough estimate of the rotational temperature, $T_{\text {rot }}=100 \mathrm{~K}$, i.e., rotational temperature of topons is 13 times higher than $T_{\text {rot }}$ for an ideal gas.

It should be noted that the thermodynamic properties of methane at low temperatures (i.e., at temperatures below the phase transition point of about $20 \mathrm{~K}$ ) were studied in [38-40]. In these works, it was shown that the characteristic maximum of the rotational component of the heat capacity of solid methane occurs at temperatures of the order of $1 \mathrm{~K}$. This value is noticeably lower than the rotational temperature of gaseous methane, which is about $5 \mathrm{~K}$. The difficulty of molecular rotations of methane leads to a decrease in the effective rotational temperature of solid methane relative to gaseous methane. This conclusion is interpretable within the framework of the topon concept.

In the high-temperature region of about $60 \mathrm{~K}$, the situation is significantly different: the structure of methane crystals is different from the low-temperature structure that occurs

at $T<20 \mathrm{~K}$. Here there is a significant excess of the effective rotational temperature of solid methane over gaseous methane.

Based on the analysis of the thermodynamic characteristics of methane crystals, it can be concluded that solid methane retains quantum features up to high temperatures of $60-65 \mathrm{~K}\left(0.7 T_{\text {tr }}\right)$. The temperature $T_{0}$ above which, according to NMR data, solid methane sharply converts to a state close to the liquid one. This temperature can be considered as the temperature of the quantum-classical transition for solid methane $[28,29]$.

\section{Conclusions}

1. Quantum manifestations in the physical properties of crystalline helium, hydrogen and methane are demonstrated using numerous experimental data.

2. It is shown that in order to estimate the size of quantum effects in these cryocrystals, it is convenient to compare their properties with the simplest cryocrystal argon, which has an extremely low de Boer quantum parameter and may be considered as a classical solid.

3. Quantum features of cryocrystals are manifested in the form of anomalous temperature dependences different from thermoactivation behavior and in the peculiarities of motion of test particles and defectsas well. The quantum features are manifested also in thermodynamic properties as the presence of a maximum of the rotational heat capacity, for example, in the case of solid methane and deuterium.

The authors are grateful to A. Zakharov for essential contribution and help in the work, and to O. Kirichek and L. Alekseeva for support of this work.

Author A.Yu. Prokhorov is grateful to the Ministry of Education and Science of the Russian Federation for finan- 
cial support of work within the framework of the project part of the State Assignment (grant No. 3.3572.2017), and author V.B. Efimov is grateful to the Ministry of Education and Science of the Russian Federation for financial support of the work within the framework of the State Assignment of the ISSP.

1. C. Cazorla and Boronat, Rev. Mod. Phys. 89, 1 (2017).

2. Physics of Cryocrystals, V.G. Manzhelii and Yu.A. Freiman (eds.), AIP Press, Woodburi, New York (1996).

3. A.F. Andreev and I.M. Lifshitz, Zh. Exp. Teor. Fiz. 56, 2057 (1969).

4. A.F. Andreev, Usp. Fiz. Nauk 118, 251 (1976).

5. V.A. Mikheev, V.L. Maidanov, and N.P. Mikhin, Fiz. Nizk. Temp. 9, 901 (1983) [Sov. Low Temp. Phys. 9, 465 (1983)].

6. K.O. Keshishev, A.Ya. Parshin, and A.V. Babkin, Pis'ma Zh. Exp. Teor. Fiz. 30, 63 (1979).

7. V.L. Tsimbalenko, Usp. Fiz. Nauk 185, 1163 (2015).

8. K.R. Atkins, Phys. Rev. 116, 1339 (1959).

9. R.O. Simmons, Invited Paper presented on Conf. of QFS, Banff, Canada (1986).

10. A.I. Golov, V.B. Efimov, and L.P. Mezhov-Deglin, Zh. Exp. Teor. Fiz. 94, 198 (1988).

11. Yu.M. Kagan and L.A. Maksimov, Zh. Exp. Teor. Fiz. 84, 792 (1984).

12. L.P. Mezhov-Deglin, V.B. Efimov, and A.I. Golov, Fiz. Nizk. Temp. 10, 99 (1984) [Sov. Low Temp. Phys. 10, 53 (1984)].

13. I.N. Krupskii, A.V. Leont'eva, L.A. Indan, and O.V. Evdokimova, Fiz. Nizk. Temp. 3, 933 (1977) [Sov. Low Temp. Phys. 3, 453 (1977)].

14. I.N. Krupskii, A.V. Leont'eva, L.A. Indan, and O.V. Evdokimova, Pis'ma Zh. Exp. Teor. Fiz. 24, 297 (1976).

15. V.I. Marchenko, Zh. Exp. Teor. Fiz. 144, 774 (2013).

16. A.V. Leont'eva and G.A. Marinin, Pis'ma Zh. Exp. Teor. Fiz. 42, 255 (1985).

17. A.I. Belousov and Yu.E. Lozovik, Fiz. Tverd. Tela 41, 1856 (1999).

18. A.V. Leont'eva, V.A. Romanusha, A.Yu. Prokhorov, et al., Ukr. Fiz. Zh. 5, 286 (1986).

19. V.A. Romanusha, A.V. Leont'eva, and A.Yu. Prokhorov, Fiz. Nizk. Temp. 12, 545 (1986) [Sov. Low Temp. Phys. 12, 309 (1986)].

20. A.Yu. Zakharov, A.V. Leont'eva, and A.Yu. Prokhorov, Vestnik of Tver. State University 4, 121 (2016).

21. K. Tomita, Phys. Rev. 89, 429 (1953).

22. C. Gearhart, Max-Planck-Institut für Wissenschaftsgeschichte, Berlin (2006).

23. A.Yu. Zakharov, A.V. Leont'eva, A.Yu. Prokhorov, and V.A. Romanusha, Vestnik of Novgorod State University 5(103), 12 (2017).

24. A.V. Leont'eva, G.A. Marinin, A.Yu. Prokhorov, and B.Ya. Sukharevskii, Fiz. Nizk. Temp. 20, 815 (1994) [Low Temp. Phys. 20, 639 (1994)].
25. O. Kirichek, A.J. Church, M.G. Thomas, and D. Cowdery, Cryogenics 52, 325 (2012).

26. O.I. Kirichek, C.R. Lavson, D.M. Jenkins, C.J.T. Ridley, and D.J. Haunes, Cryogenics 88, 101 (2017).

27. O. Kirichek, E.V. Savchenko, C.R. Lawson, I.V. Khyzhniy, D.M. Jenkins, S.A. Uyutnov, M.A. Bludov, and D.J. Haynes, J. Phys.: Conf. Ser. 969, 12006 (2018).

28. A.Yu. Zakharov, A.V. Leont'eva, A.Yu. Prokhorov, and A.I. Erenburg, Fiz. Tverd. Tela 56, 1446 (2014).

29. A.Yu. Zakharov, A.V. Leont'eva, A.Yu. Prokhorov, and A.I. Erenburg, J. Low Temp. Phys. 185, 40 (2016).

30. L.P. Pauling, Phys. Rev. 36, 430 (1931).

31. G. Herzberg, Molecular Spectra and Molecular Structure II: Infrared and Raman of Polyatomic Molecules, Van Nostrand, Princeton (1991).

32. A.V. Leont'eva, A.Y. Prokhorov, A.Y. Zakharov, and A.I. Erenburg, J. Exp. Phys. 2014, Art.Y.D. 127050 (2014).

33. A.I. Erenburg, A.Yu. Zakharov, A.V. Leont'eva, and A.Yu. Prokhorov, Cryogenics 78, 51 (2016).

34. A.Yu. Zakharov, A.V. Leont'eva, and A.Yu. Prokhorov, J. Physics: Conf. Ser. 441, 012060 (2018).

35. E. Shabalin, A. Fedorov, E. Kulagin, S. Kulikov, V. Melikhov, and D. Shabalin, Preprint of the Joint Institute for Nuclear Research. Dubna (2008).

36. L. Brillouin, Die Quantenstatistik und ihre Anwendung auf die Elektronentheorie der Metalle, Springer, Berlin (1931).

37. L.D. Landau and E.M. Lifshitz, Statistical Physics, Elsevier, Amsterdam (2008).

38. K. Nishiyama, Y. Kataoka, and T. Yamamoto, Progr. Theor. Phys. 43, 1121 (1970).

39. Y. Kataoka and T. Yamamoto, Prog. Theor. Phys. Suppl. E 68, 436 (1968).

40. T. Yamamoto and Y. Kataoka, Phys. Rev. Lett. 21, 1 (1968).

\section{Квантові ефректи в кріокристалах у широкому температурному діапазоні}

\section{А. Леонтьєва, А. Прохоров, В. Романуша, В. Єфрімов}

У зв'язку з постійно зростаючим інтересом до кріокристалів у наукових та прикладних задачах необхідно ретельне вивчення їх різних властивостей і характеристик. Наведено аналіз експериментальних аномалій ряду фізичних властивостей квантових кріокристалів (гелій, водень, метан) в області низьких температур, де термічні флуктуації різко зменшуються, а роль квантових флуктуацій стає домінуючою. Це проявляється не тільки в поступальному русі атомів або дефектів в таких кріокристалах, як гелій і неон, але й в обертальних ступенях свободи, наприклад, твердого метану та водню.

Ключові слова: гелій, водень, метан, аргон, квантові ефекти, квантові параметри, обертальна теплоємність. 
Квантовые эффректы в криокристаллах в широком температурном диапазоне

\section{А. Леонтьева, А. Прохоров, В. Романуша, В. Ефимов}

В связи с постоянно растущим интересом к криокристаллам в научных и прикладных задачах необходимо тщательное изучение их различных свойств и характеристик. Представлен анализ экспериментальных аномалий ряда физических свойств квантовых криокристаллов (гелий, водород, метан) в области низких температур, где термические флуктуации резко уменьшаются, а роль квантовых флуктуаций становится доминирующей. Это проявляется не только в поступательном движении атомов или дефектов в таких криокристаллах, как гелий и неон, но и во вращательных степенях свободы, например, твердого метана и водорода.

Ключевые слова: гелий, водород, метан, аргон, квантовые эффекты, квантовые параметры, вращательная теплоемкость. 